\title{
Electrooxidation of Ethanol on Pt and PtRu Surfaces Investigated by ATR Surface-Enhanced Infrared Absorption Spectroscopy
}

\author{
Márcio F. Silva, ${ }^{a}$ Bruno C. Batista, ${ }^{b}$ Emerson Boscheto, ${ }^{b}$ Hamilton Varela ${ }^{*, b, c}$ and \\ Giuseppe A. Camara*a
}

\author{
${ }^{a}$ Departamento de Química, Universidade Federal do Mato Grosso do Sul, \\ CP 549, 79070-900 Campo Grande-MS, Brazil \\ ${ }^{b}$ Instituto de Química de São Carlos, Universidade de São Paulo, \\ CP 780, 13560-970 São Carlos-SP, Brazil
}
${ }^{c}$ Ertl Center for Electrochemistry and Catalysis, GIST, Cheomdan-gwagiro 261, Buk-gu, 500-712 Gwangju, South Korea

\begin{abstract}
Neste trabalho, investigou-se pela primeira vez a eletrooxidação de etanol em eletrodepósitos de Pt e PtRu em meio ácido através da técnica de absorção e reflexão de infravermelho em superfície com reflexão total atenuada (ATR-SEIRAS) in situ. O desenho experimental elimina as fracas absorbâncias associadas a espécies adsorvidas, usualmente observadas para superfícies eletrodepositadas (rugosas), e permite que se acompanhe o recobrimento superficial por $\mathrm{CO}$ em função do potencial, para ambos os catalisadores. A dinâmica da adsorção-oxidação de CO foi acompanhada por ATR-SEIRAS (para quatro concentrações de etanol) e correlacionada com expressões derivadas de um modelo cinético simples. A análise cinética sugere que o desenvolvimento da camada de $\mathrm{CO}$ não é influenciado pela presença de Ru ou pela concentração de etanol. Os resultados apontam que a quebra da ligação $\mathrm{C}-\mathrm{C}$ independe do recobrimento com $\mathrm{Ru}$ e provavelmente acontece em sítios de Pt.
\end{abstract}

Herein, it was investigated for the first time the electro-oxidation of ethanol on Pt and PtRu electrodeposits in acidic media by using in situ surface enhanced infrared absorption spectroscopy with attenuated total reflection (ATR-SEIRAS). The experimental setup circumvents the weak absorbance signals related to adsorbed species, usually observed for rough, electrodeposited surfaces, and allows a full description of the CO coverage with the potential for both catalysts. The dynamics of adsorption-oxidation of $\mathrm{CO}$ was accessed by ATR-SEIRAS experiments (involving four ethanol concentrations) and correlated with expressions derived from a simple kinetic model. Kinetic analysis suggests that the growing of the $\mathrm{CO}$ adsorbed layer is nor influenced by the presence of Ru neither by the concentration of ethanol. The results suggest that the $\mathrm{C}-\mathrm{C}$ scission is not related to the presence of $\mathrm{Ru}$ and probably happens at Pt sites.

Keywords: ethanol electrooxidation, adsorbed CO, platinum, ruthenium, ATR-SEIRAS

\section{Introduction}

The search for materials able to electrooxidize alcohols used as fuels in power sources has experienced an impressive increasing in the last years. ${ }^{1-6}$ Such interest is motivated by the high energy densities and easier storage, transport and handling associated with these compounds.

In this context, ethanol has motivated renewed interest for application in direct alcohol fuel cells due to its relative high energetic content $\left(12 \mathrm{~F} \mathrm{~mol}^{-1}\right)$, abundance and low toxicity.

*e-mail: varela@iqsc.usp.br, giuseppe.silva@ufms.br
Among the electrocatalysts investigated, platinum-ruthenium surfaces (hereafter designed PtRu) occupy a prominent place due to the Ru capability to produce oxygen containing species at low potentials. ${ }^{7}$ For this reason, several works report the catalytic activity of PtRu supported nanoparticles towards ethanol oxidation, ${ }^{8-13}$ but factors as low coordination number, interaction with carbon support, among others make the behavior observed for nanoparticles different from that found for extended surfaces.

On this subject, electrodeposited surfaces are important to be used as models in fundamental studies, because they provide a surface of intermediary complexity among 
extended surfaces and nanoparticles, once factors as high heterogeneity and interaction with carbon supports are absent. Moreover, electrodeposits are relatively easy to prepare if compared with carbon supported nanoparticles and single crystals. Concerning electrodeposits, the literature describes the manufacture of PtRu catalysts by the application of potentials close to $0.0 \mathrm{~V} v s$. RHE, enough low to allow the electroreduction of $\mathrm{Pt}^{4+}$ and $\mathrm{Ru}^{3+}$ ions onto gold substrates. ${ }^{7,14,15}$

Unfortunately, using electrodeposited surfaces causes a noticeable reduction of the band intensities referent to adsorbed CO. ${ }^{16}$ The reason for this effect probably originates from scattering of part of the infrared radiation provoked by the rough structure of the surface. ${ }^{16,17}$ As a consequence, important information concerning the role played by $\mathrm{CO}$ during the electrooxidation of organic molecules is often lost when investigating electrodeposits.

As an attempt to overcome this difficulty, surface enhanced infrared absorption spectroscopy with attenuated total reflection (ATR-SEIRAS) has been regarded as a powerful tool for probing electrochemical reactions, since it allows the visualization of the adsorbates without interference of the solution. ${ }^{18-20}$ Ultimately, ATR-SEIRAS can be very useful to gain some new information about the early stages of ethanol electrooxidation and its influence on the subsequent steps of the reaction.

On this sense, here we report the electrooxidation of ethanol on Pt and PtRu films by in situ ATR-SEIRAS. To our knowledge, this is the first ATR-SEIRAS study probing a bimetallic surface prepared by electrodeposition towards ethanol electrooxidation. A parental system involving the electrodeposition of PtRu on gold substrate for methanol oxidation is known, ${ }^{21}$ but otherwise the literature is scarce on this kind of data.

\section{Experimental}

Sulfuric acid (Mallinckrodt, 99.8\%), and ethanol (J. T. Baker, 99.9\%) were used as received. All solutions were prepared with high purity water. Nitrogen (99.999\%) was used to purge the electrolyte solution before and during the experiments.

The working electrodes were Pt and PtRu films deposited on a rectangular Si prism with geometric area of $7.3 \mathrm{~cm}^{2}$. The preparation of the deposits was performed in two steps. Firstly, a gold film was deposited on the $\mathrm{Si}$ prism according to a procedure previously described. ${ }^{22}$ Afterwards, Pt and PtRu were electrodeposited from $\mathrm{H}_{2} \mathrm{PtCl}_{6}$ and $\mathrm{RuCl}_{3}$ aqueous solutions in $0.5 \mathrm{~mol} \mathrm{~L}^{-1} \mathrm{H}_{2} \mathrm{SO}_{4}$ and $0.25 \mathrm{~V} v s$. RHE for $4 \mathrm{~min}$. This procedure resulted in surfaces with roughness factor of about 7 . The roughness factor was calculated by simply taking the ratio between the electrochemical surface area and the geometric area.

For the estimation of the real surface area, the electrodes were saturated with carbon monoxide by bubbling the gas for $10 \mathrm{~min}$ at $0.05 \mathrm{~V} v \mathrm{~s}$. RHE in the solution containing only $0.5 \mathrm{~mol} \mathrm{~L}^{-1} \mathrm{H}_{2} \mathrm{SO}_{4}$. The excess of $\mathrm{CO}$ was then eliminated from the solution by bubbling pure $\mathrm{N}_{2}$ for $10 \mathrm{~min}$ and cyclic voltammograms were recorded at $5 \mathrm{mV} \mathrm{s}^{-1}$. It was used a charge of $420 \mu \mathrm{C} \mathrm{cm}^{-2}$ of real area for the oxidation of a $\mathrm{CO}$ monolayer, which assumes that all adsorbed $\mathrm{CO}$ species are linearly bonded. This assumption is justified on the fact that FTIR spectra for CO adsorbed on PtRu alloys of different compositions show only on-top $\mathrm{CO}^{23}$

All potentials were measured against a reversible hydrogen electrode in the corresponding support electrolyte and are presented in the same scale. A high area Pt foil was used as the counter electrode. It should be noticed that after the gold layer is prepared it is also possible to deposit metal nanoparticles on the top of it and study processes at those electrodes..$^{24,25}$

In situ ATR-SEIRAS experiments were performed with a Nicolet Nexus 670 spectrometer equipped with a MCT detector and a homemade single-reflection accessory. The spectral data were acquired as interferograms using the rapid scan mode (five interferograms per $\mathrm{s}$ ) at a resolution of $8 \mathrm{~cm}^{-1}$. Spectra were obtained during a slow cyclic voltammogram $\left(1 \mathrm{mV} \mathrm{s}^{-1}\right)$ in the potential range comprised between 0.05-1.40 V (for Pt) and 0.05-0.80 V (for PtRu). The spectra were computed from an average of 25 interferograms. The reference spectrum was taken at $1.40 \mathrm{~V}$ (for Pt) and $0.8 \mathrm{~V}$ (for PtRu) in the presence of ethanol for following $\mathrm{CO}$ bands. In this configuration, negative bands correspond to species formed or whose concentration has increased at the sampling potential, whereas positive bands are associated with a diminution of the concentration of the species. All the experiments were carried out at $25.0 \pm 1.0^{\circ} \mathrm{C}$.

Because the PtRu film used for ATR-SEIRAS is electrodeposited on a Si prism, it is not possible to analyze its composition, but the same procedure was applied to a gold flag which resulted in a PtRu atomic composition of 60:40, as determined by EDS. Thus, it was assumed that the atomic compositions are the same for both cases. The real atomic composition was chosen because it is in a range which presents the maximum catalytic activity towards ethanol oxidation. ${ }^{26,27}$

\section{Results and Discussion}

The electrooxidation of ethanol followed by ATR-SEIRAS

Figure 1 shows the first cyclic voltammograms obtained during the oxidative stripping of a $\mathrm{CO}$ monolayer for both 
Pt and PtRu ATR electrodeposits. For these experiments, $\mathrm{CO}$ was adsorbed at $0.05 \mathrm{~V}$ for $10 \mathrm{~min}$ and the cell was then purged with argon for $30 \mathrm{~min}$, after which the potential was scanned at $5 \mathrm{mV} \mathrm{s}^{-1}$. The currents were normalized by the real area calculated by integration of the stripping currents. These preliminary experiments involving only the $\mathrm{CO}$ adsorption were important since it can be correlated to the formation of $\mathrm{CO}$ adlayers from ethanol adsorption, as will be discussed in the due course.

For pure Pt, it can be seen a small pre-peak at $0.42 \mathrm{~V}$ followed by a full developed peak at $0.68 \mathrm{~V}$. The addition of ruthenium on the composition of the electrode results in a decrease of the main peak potential to $0.49 \mathrm{~V}$, which represents an overpotential lowering of about $0.19 \mathrm{~V}$. This behavior has been already explained in terms of electronic and bifunctional effects. ${ }^{28}$

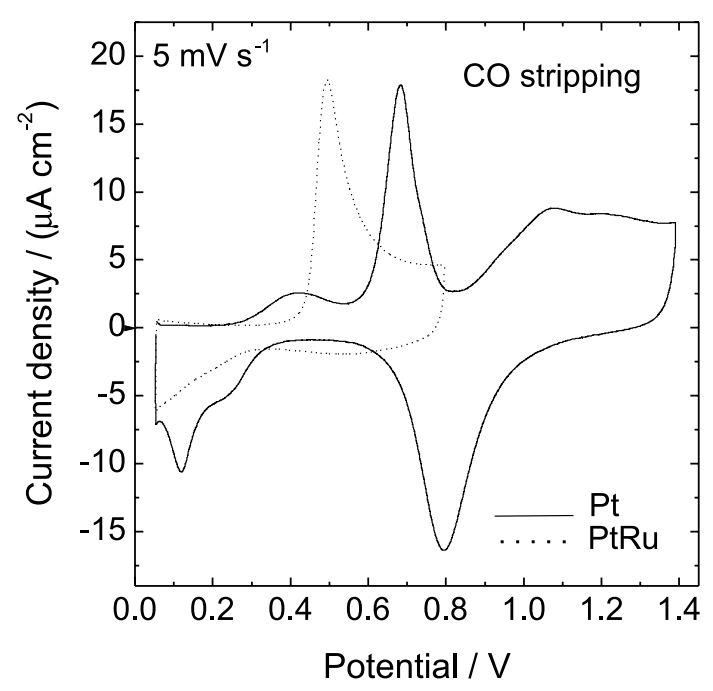

Figure 1. Cyclic voltammograms obtained at $5 \mathrm{mV} \mathrm{s}^{-1}$ during an oxidative $\mathrm{CO}$ stripping experiment. The figure compares the results found for $\mathrm{Pt}$ and PtRu electrodeposits. The experiments were performed in $0.5 \mathrm{~mol} \mathrm{~L}^{-1}$ $\mathrm{H}_{2} \mathrm{SO}_{4}$.

Figure 2a shows spectra for some selected potentials obtained during a $1 \mathrm{mV} \mathrm{s}^{-1} \mathrm{scan}$ for a Pt ATR-electrode in contact with a solution containing $2 \mathrm{~mol} \mathrm{~L}^{-1}$ ethanol and $0.5 \mathrm{~mol} \mathrm{~L}^{-1} \mathrm{H}_{2} \mathrm{SO}_{4}$. The gray-scale picture in Figure $2 \mathrm{~b}$ shows in details the evolution of the $\mathrm{CO}$ band for PtRu during the voltammetric scan. Analogous experiments were obtained for Pt and PtRu electrodes for four different ethanol concentrations. Despite some minor differences in the potential of $\mathrm{CO}$ oxidation (which will be addressed later), all experiments displayed a spectral evolution similar to that shown in Figures 2a and 2b.

During the positive scan, there is a slight increase in the quantity of adsorbed $\mathrm{CO}$ between the potentials of $0.1-0.5 \mathrm{~V}$ (Figure 2a). In this range of potentials, adsorbed hydrogen is being oxidized and the platinum surface is accordingly free for ethanol adsorption and decomposition. At about $0.6 \mathrm{~V}$, the poison layer starts being oxidized and is fully consumed at $c a$. $0.8 \mathrm{~V}$. During the negative scan, the poison adlayer starts to build-up again at about $0.6 \mathrm{~V}$ and the $\mathrm{CO}$ band intensity gradually increases when the potential is decreased.
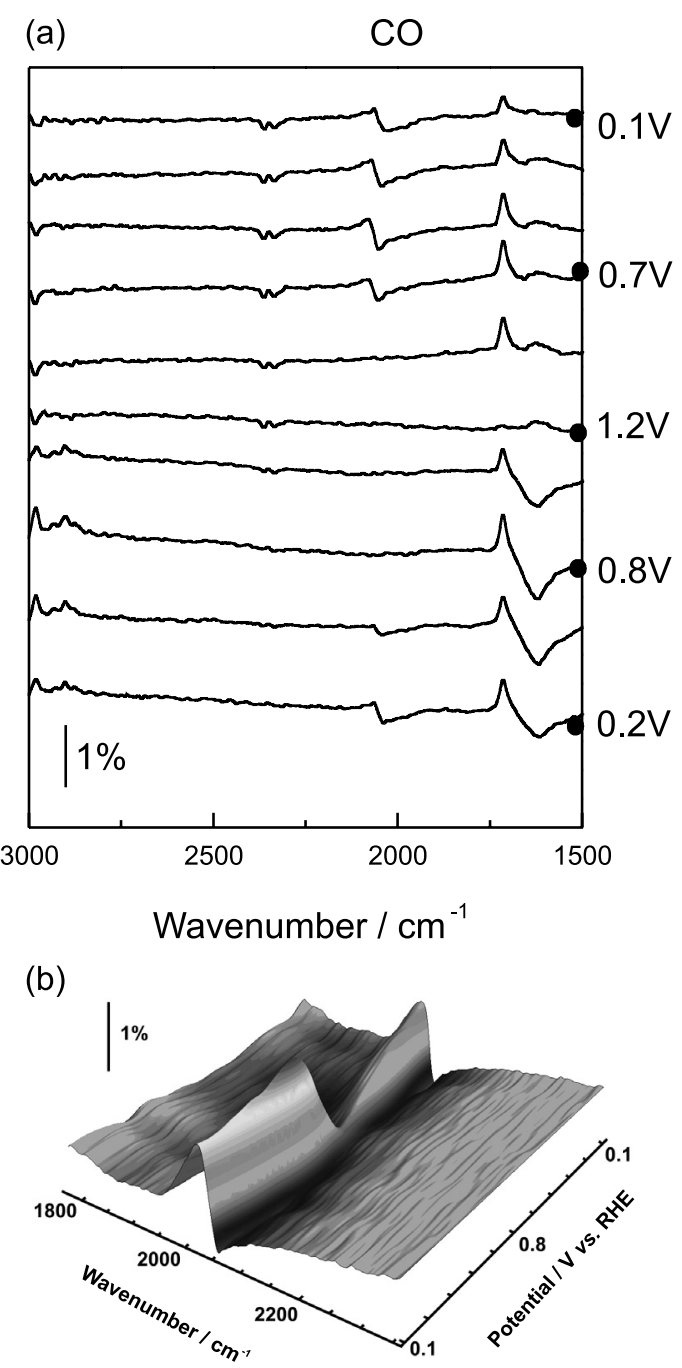

Figure 2. (a) Typical spectra obtained during experiments of ethanol electrooxidation on Pt. In this specific case, [ethanol] $=2 \mathrm{~mol} \mathrm{~L}^{-1}$; $\left[\mathrm{H}_{2} \mathrm{SO}_{4}\right]=0.5 \mathrm{~mol} \mathrm{~L}^{-1}$. In (b) the gray-scale picture focuses on the dynamics of the $\mathrm{CO}$ band as function of the potential for PtRu.

Figures 3 and 4 display the complete series of integrated bands for adsorbed $\mathrm{CO}$ on Pt and PtRu electrodes as a function of the potential. Experiments were performed for four different concentrations of ethanol (indicated in the figures). The corresponding voltammetric profiles are also shown for comparison. Here, it is important to note that $\mathrm{CO}$ integrated areas were normalized by the maximum $\mathrm{CO}$ band intensity in each case in order to take into account the lower $\mathrm{CO}$ absorption coefficient observed for PtRu surfaces when compared 

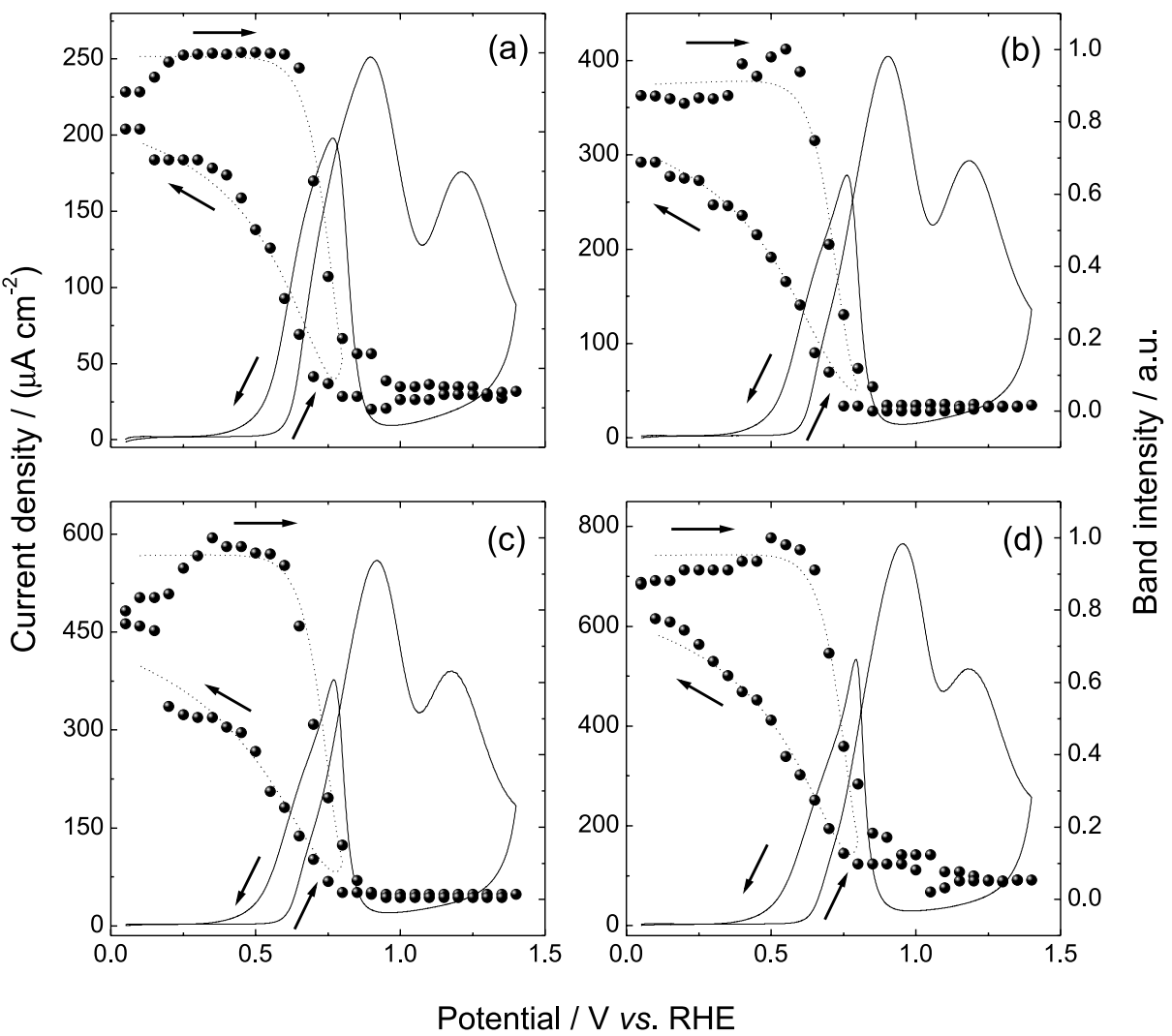

Figure 3. Cyclic voltammograms and integrated band intensities $v s$. adsorbed $\mathrm{CO}$ on a Pt electrodeposit. The experiments were performed in the presence of $0.5 \mathrm{~mol} \mathrm{~L}^{-1} \mathrm{H}_{2} \mathrm{SO}_{4}$ and ethanol concentrations of (a) $0.2 \mathrm{~mol} \mathrm{~L}^{-1}$, (b) $0.5 \mathrm{~mol} \mathrm{~L}^{-1}$, (c) $1 \mathrm{~mol} \mathrm{~L}^{-1}$ and (d) $2 \mathrm{~mol} \mathrm{~L}^{-1}$. The dotted lines connecting the filled circles accounts for the curve fitted with equations 1 and 2 .

to Pt (caused by stronger dipole-dipole coupling in the presence of Ru).${ }^{14}$ However, since the $\mathrm{CO}$ bands are not being directly compared, this procedure will not affect the forthcoming analysis.

In a general way, the same trends already observed in Figure 2 are shown. Namely, the growing of the currents in the voltammograms for both catalysts coincides with the consumption of the $\mathrm{CO}$ adlayer to produce $\mathrm{CO}_{2}$. As the potential is reversed, the $\mathrm{CO}$ adlayer is regenerated for lower potentials.

\section{Modeling the dynamics of $\mathrm{CO}$ adsorption}

It is known that the electrooxidation of ethanol is a complex process involving the presence of several adsorbed intermediates like acetaldehyde and acetic acid. ${ }^{18}$ However, although utterly simple, the model discussed below revealed good adjustment to the experimental data and allowed the exploration of important kinetic parameters.

Focusing initially on the dynamics of adsorbed CO, it was used the following set of equations to model the kinetics of production and oxidation of $\mathrm{CO}_{\mathrm{ad}}$ during the voltammetric sweeps.
The kinetics of $\mathrm{CO}$ production was modeled to be rate-determined by the interaction between ethanol and two platinum free sites. The modeling of any other electrooxidation products than $\mathrm{CO}$ is beyond the scope of this study. The oxidation process was best fitted by assuming a Butler-Volmer kinetics proportional to the number of occupied sites. The following set of chemical steps was considered:

$2 \mathrm{Pt}+\mathrm{EtOH} \stackrel{\mathrm{k}_{\mathrm{p}}}{\rightarrow} \mathrm{Pt}-\mathrm{CO}+\mathrm{Pt}+$ others
$\mathrm{Pt}-\mathrm{CO}+\mathrm{H}_{2} \mathrm{O} \rightarrow \mathrm{Pt}+\mathrm{CO}_{2}+2 \mathrm{H}^{+}+2 \mathrm{e}^{-}$

(Reaction 1) (Reaction 2)

Reactions 1 and 2 are translated in the following set of differential equations:

$\frac{\mathrm{d} \theta}{\mathrm{dt}}=\mathrm{k}_{\mathrm{p}}(1-\theta)^{2}-\mathrm{k}_{\mathrm{OX}} \theta \mathrm{e}^{\mathrm{F}\left(\varphi-\varphi_{0}\right)}$

$\frac{\mathrm{d} \theta}{\mathrm{dt}}= \pm$ vel

Equation 1 represents the evolution of the $\mathrm{CO}$ coverage $(\theta)$ that is determined by a term dependent on 


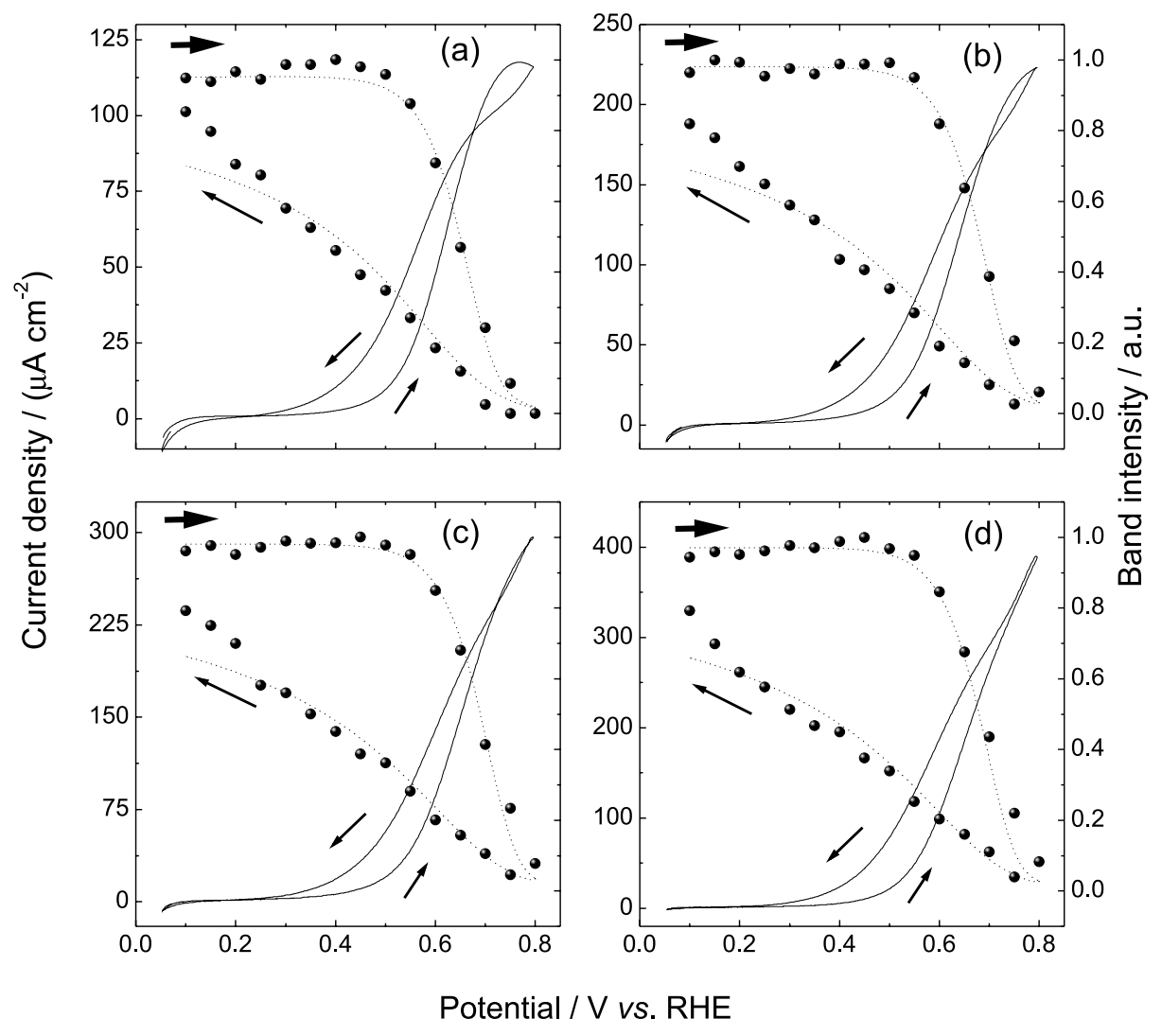

Figure 4. Cyclic voltammograms and normalized integrated band intensities for adsorbed $\mathrm{CO}$ on a PtRu (60:40) electrodeposit. Experimental conditions as in Figure 3. The dotted line connecting the filled circles accounts for the curve fitted with equations 1 and 2.

the constant of poisoning $\left(\mathrm{k}_{\mathrm{p}}\right)$ and the second power of the available free sites $(1-\theta)$. The second term accounts for $\mathrm{CO}$ oxidation according to a Butler-Volmer expression conditioned to the amount of poison available. The second equation describes how the potential of the electrode $(\phi)$ evolves as a function of time. In the present case (i.e., for cyclic voltammetric experiments), it was assumed a linear dependence.

The quality of the fitting was monitored by the $\mathrm{R}^{2}$ term, the coefficient of determination of the model:

$\mathrm{R}^{2}=\frac{\Sigma\left(\mathrm{s}_{\mathrm{i}}-\mathrm{e}_{\mathrm{i}}\right)^{2}}{\Sigma\left(\mathrm{e}_{\mathrm{i}}\right)^{2}}$

$\mathrm{R}$ is ratio between the summation of the square of the residual, i.e., the difference between the simulated $\left(\mathrm{s}_{\mathrm{i}}\right)$ and the experimental $\left(e_{i}\right)$ data for a given value of potential, and the overall sum of the experimental values to the second power. $\mathrm{R}^{2}$ is a measure used in empirical model-building to account for the quality of the model in representing the observed values. The obtained parameters are given in Table 1.

It seems that the rate constant of the poisoning process, i.e., the build-up of the $\mathrm{CO}$ adsorbed layer is not influenced by the presence of Ru. In contrast, the oxidation of adsorbed
$\mathrm{CO}$ is shifted to less positive potentials when the PtRu surface is used, as clearly seen in the onset potential. This finding can be readily interpreted as the property of $\mathrm{Ru}$ atoms to provide surface oxygenated species at considerably lower potentials. Indeed, it is well-known that $\mathrm{PtRu}$ anticipates the onset of $\mathrm{CO}_{2}$ formation during the electrooxidation of small organic molecules, as methanol, ${ }^{29}$ and formaldehyde ${ }^{14}$, but studies performed with ethanol suggest that $\mathrm{Ru}$ fails to promote the scission of the $\mathrm{C}-\mathrm{C}$ bond. ${ }^{26}$ Therefore, the similar $\mathrm{CO}$ adsorption parameters for both catalysts merely reflect the fact that $\mathrm{Ru}$ acts only as an oxygen-source (during the electrooxidation), but do not influence the establishment of the $\mathrm{CO}$ adlayer observed during the earlier steps of adsorption.

At this point, it is important to clarify that we are assuming that $\mathrm{Ru}$ does adsorb CO. Indeed, previous papers unequivocally showed $\mathrm{CO}$ adsorption on $\mathrm{Ru} .^{30,31}$ It seems that $\mathrm{Ru}$ acts as an oxygen-source but is not able to significantly change the strength of $\mathrm{CO}$ adsorption. Consequently, it fails to promote the scission of the $\mathrm{C}-\mathrm{C}$ bonds from ethanol and the population of $\mathrm{CO}$ seems to be virtually unaffected by the presence of $\mathrm{Ru}$, which merely provokes the step of oxidation to start earlier than on $\mathrm{Pt}$ (as shown by the stripping curves of Figure 1). 
Table 1. Adjusted parameters for Pt and PtRu electrodeposits in different ethanol concentrations (indicates)

\begin{tabular}{|c|c|c|c|c|c|}
\hline \multicolumn{2}{|c|}{ Ethanol Concentration / $\left(\mathrm{mol} \mathrm{L}^{-1}\right)$} & \multirow{2}{*}{$\begin{array}{c}0.2 \\
0.97\end{array}$} & \multirow{2}{*}{$\begin{array}{c}0.5 \\
0.93\end{array}$} & \multirow{2}{*}{$\begin{array}{c}1.0 \\
0.95\end{array}$} & \multirow{2}{*}{$\begin{array}{c}2.0 \\
0.96\end{array}$} \\
\hline Pt exp2 & $\phi_{0} / \mathrm{V}$ & & & & \\
\hline & $\mathrm{k}_{\mathrm{p}} / \mathrm{s}^{-1}$ & 0.0055 & 0.004 & 0.003 & 0.0045 \\
\hline & $\mathrm{R}^{2}$ & 0.996748 & 0.995572 & 0.990451 & 0.995894 \\
\hline & $\phi_{\text {onset }} / \mathrm{V}(\mathrm{mod})$ & 0.67 & 0.63 & 0.64 & 0.64 \\
\hline & $\phi_{\text {onset }} / \mathrm{V}(\exp )$ & 0.64 & 0.60 & 0.61 & 0.64 \\
\hline \multirow[t]{5}{*}{ PtRu exp2 } & $\phi_{0} / \mathrm{V}$ & 0.87 & 0.9 & 0.91 & 0.9 \\
\hline & $\mathrm{k}_{\mathrm{P}} / \mathrm{s}^{-1}$ & 0.0045 & 0.004 & 0.0035 & 0.0035 \\
\hline & $\mathrm{R}^{2}$ & 0.995086 & 0.995692 & 0.996215 & 0.996019 \\
\hline & $\phi_{\text {onset }} / \mathrm{V}(\mathrm{mod})$ & 0.57 & 0.60 & 0.61 & 0.60 \\
\hline & $\phi_{\text {onset }} / \mathrm{V}(\exp )$ & 0.54 & 0.57 & 0.58 & 0.57 \\
\hline
\end{tabular}

Focusing now on the effect of ethanol concentration, it becomes apparent from the data given in Table 1 that it has only a minor, if any, impact on the adsorption and on the electrooxidation of carbon monoxide. The only visible effect is a little delay in the potentials, in which the oxidation currents start to rise on $\mathrm{Pt}$ (ca. $50 \mathrm{mV}$, not shown) when the ethanol concentration is increased. For PtRu, the potential-delay is depreciable when the concentration of ethanol is increased.

This behavior can be rationalized if it is assumed that reaction 2 depends on the concentration of ethanol. Indeed, reaction 2 is assumed to occur through a LangmuirHinshelwood mechanism, ${ }^{32}$ in which the rate of the reaction is expected to depend on the coverage of both adsorbed reactants $\left(\mathrm{CO}\right.$ and $\left.\mathrm{H}_{2} \mathrm{O}\right)$. Thus, the increasing difficulty to generate $\mathrm{CO}_{2}$ at high concentrations of ethanol is assumed to be caused by the blockage of the surface by organic intermediates that inhibit the formation of oxygen sources. This increasing difficulty explains why higher potentials are required to electrooxidize ethanol at high concentrations. The model also explains why the effect is less dramatic on PtRu surfaces. In this case, the relative facility of Ru to generate oxygen-sources seems to prevent the preferential adsorption of any organic species/residues from ethanol. Consequently, the PtRu/ethanol system is virtually not affected by the concentration of the alcohol.

Contrarily, Table 1 suggests that reaction 1 does not depend on the concentration of ethanol, as suggested by the similar values of $\mathrm{k}_{\mathrm{p}}$. These results are in line with those published by Camara and Iwasita, ${ }^{32}$ who investigated the electrooxidation of ethanol on $\mathrm{Pt}$ at distinct ethanol concentrations by using in situ FTIR (thin layer configuration). ${ }^{32}$ There, the authors demonstrate that the increasing difficulty to generate $\mathrm{CO}_{2}$, observed when the concentration of ethanol is increased, is not accompanied by corresponding changes in the band intensity for adsorbed
$\mathrm{CO}$, i.e., the $\mathrm{CO}$ surface coverage is not dependent on the ethanol concentration. ${ }^{32}$ Based on both results, it is proposed that at relative low potentials, the $\mathrm{CO}$ adsorption is faster than any other steps involved in the occurrence of reactions 1 and 2. If this is the case, $\mathrm{CO}$ adsorption is expected to be preferential over any other residues (e.g. $-\mathrm{CH}_{\mathrm{x}}$ species) and will not depend on the ethanol concentration. At high potentials, the situation changes and the $\mathrm{CO}$ oxidation becomes faster than its formation, and no $\mathrm{CO}$ accumulates on the surface.

It is also interesting to note that the effect of ruthenium on the oxidation of $\mathrm{CO}$ in the presence of ethanol is much less pronounced than that found during the stripping experiment. This is corroborated by the fact that Ru increases the rate of reaction 2 but is unable to catalyze reaction 1, whose steps occur only in the presence of ethanol.

\section{Conclusions}

ATR-SEIRAS experiments performed on Pt and for the first time for PtRu electrodeposited films show that on both surfaces, $\mathrm{CO}$ is formed at potentials as low as $0.1 \mathrm{~V}$ and remains adsorbed on the surfaces, blocking surface sites and thus inhibiting ethanol oxidation.

The modeled kinetics of $\mathrm{CO}$ production suggest that the establishment of the $\mathrm{CO}$ adsorbed layer is not influenced by the presence of $\mathrm{Ru}$, whilst its oxidation is clearly favored in the presence of $\mathrm{Ru}$. $\mathrm{Ru}$ is able to anticipate the oxidation steps but is not able to significantly change the strength of $\mathrm{CO}$ adsorption. Consequently, the population of $\mathrm{CO}$ seems to be virtually unaffected by the presence of Ru. For pure $\mathrm{Pt}$, a little delay in the onset potential is observed when the ethanol concentration is increased. This effect is not present on PtRu.

Both behaviors are rationalized in terms of a competition between organic molecules and oxygen sources for the 
same sites. For $\mathrm{Pt}$, the inhibition of $\mathrm{CO}_{2}$ production at high concentrations of ethanol seems to be caused by the blockage of the surface by organic intermediates that prevent the adsorption of oxygen sources. The effect is less dramatic on PtRu surfaces due to the relative facility of $\mathrm{Ru}$ to generate oxygen-sources, which prevents the excess of adsorbed species/residues from ethanol. Consequently, the PtRu/ethanol system is virtually not affected by the concentration of the alcohol.

\section{Acknowledgments}

G. A. Camara acknowledges financial assistance from CNPq (grants 576742/2008-2 and 554591/2010-3) and DFI/ UFMS for EDS analysis. H. Varela acknowledges FAPESP (grant 09/07629-6) and CNPq (grant 302698/2007-8 BCB:141753/2009-2) for financial support. M. F. Silva is indebted to CAPES for a fellowship.

\section{References}

1. Kowal, A.; Li, M.; Shao, M.; Sasaki, K.; Vukmirovic, M. B.; Zhang, J.; Marinkovic, N. S.; Liu, P.; Frenkel, A. I.; Adzic, R. R.; Nat. Mater. 2009, 8, 325.

2. Oliveira, R. T. S.; Santos, M. C.; Marcussi, B. G.; Tanimoto, S. T.; Bulhões, L. O. S.; Pereira, E. C.; J. Power Sources 2006, 157, 212.

3. Lima, F. H. B.; Profeti, D.; Lizcano-Valbuena, W. H.; Ticianelli, E. A.; Gonzalez, E. R.; J. Electroanal. Chem. 2008, 617, 121.

4. Gomes, J. F.; Busson, B.; Tadjeddine, A.; Tremiliosi-Filho, G.; Electrochim. Acta 2008, 53, 6899.

5. Camargo, A. P. M.; Previdello, B. A. F.; Varela, H.; Gonzalez, E. R.; Electrochem. Commun. 2010, 12, 140.

6. Farias, M. J. S.; Camara, G. A.; Tanaka, A. A.; J. Solid State Electrochem. 2007, 11, 1465.

7. Giz, M. J.; Camara, G. A.; Maia, G.; Electrochem. Commun. 2009, 11, 1586.

8. Zhou, W. J.; Zhou, Z. H.; Song, S. Q.; Li, W. Z.; Sun, G. Q.; Tsiakaras, P.; Xin, Q.; Appl. Catal., B 2003, 46, 273.

9. Wang, H.; Jusys, Z.; Behm, R. J.; J. Power Sources 2006, 154, 351.

10. Song, S. Q.; Zhou, W. J.; Zhou, Z. H.; Jiang, L. H.; Sun, G. Q.; Xin, Q; Leontidis, V.; Kontou, S.; Tsiakaras, P.; Int. J. Hydrogen Energy 2005, 30, 995.
11. Neto, A. O.; Dias, R. R.; Tusi, M. M.; Linardi, M.; Spinacé, E. V.; J. Power Sources 2007, 166, 87.

12. Colmati, F.; Antolini, E.; Gonzalez, E. R.; J. Power Sources 2006, 157, 98.

13. Liu, C. W.; Chang, Y. W.; Wei, Y. C.; Wang, K. W.; Electrochim. Acta 2011, 56, 2574.

14. de Lima, R. B.; Massafera, M. P.; Batista, E. A.; Iwasita, T.; J. Electroanal. Chem. 2007, 603, 142.

15. Glajchman, P.; Wordell, D. H.; Giz, M. J.; Camara, G. A.; J. Power Sources 2010, 195, 7221.

16. de Lima, R. B.; Paganin, V.; Iwasita, T.; Vielstich, W.; Electrochim. Acta 2003, 49, 85.

17. Mello, G.A. B.; Giz, M. J.; Camara, G.A.; Crisci, A.; Chatenet, M.; J. Electroanal. Chem. 2011, 660, 85.

18. Shao, M. H.; Adzic, R. R.; Electrochim. Acta 2005, 50, 2415.

19. Heinen, M.; Jusys, Z.; Behm, R. J.; J. Phys. Chem. C 2010, $114,9850$.

20. Boscheto, E.; Batista, B. C.; Lima, R. B.; Varela, H.; J. Electroanal. Chem. 2010, 642, 17.

21. Li, Q. X.; Zhou, X. J.; Li, J. G.; Xu, Q. J.; Acta Phys. Chim. Sin. 2010, 26, 1488.

22. Miyake, H.; Osawa, M.; Electrochem. Commun. 2002, 4, 973.

23. Lin, W. F.; Vielstich, W.; J. Phys. Chem. B 1999, 103, 3250.

24. Watanabe, M.; Sato, T.; Kunimatsu, K.; Uchida, H.; Electrochim. Acta 2008, 53, 6928.

25. Sato, T.; Kunimatsu, K.; Okaya, K.; Yano, H.; Watanabe, M.; Uchida, H.; Energy Environ. Sci. 2011, 4, 433.

26. Camara, G. A.; de Lima, R. B.; Iwasita, T.; J. Electroanal. Chem. 2005, 585, 128.

27. Camara, G. A.; de Lima, R. B.; Iwasita, T.; Electrochem. Commun. 2004, 6, 812.

28. Petrii, O. A.; J. Solid State Electrochem. 2008, 12, 609.

29. Iwasita, T.; Hoster, H.; John-Anacker, A.; Lin, W. F.; Vielstich, W.; Langmuir 2000, 16, 522.

30. Gao, F.; Goodman, D. W.; Langmuir 2010, 26, 16540.

31. Iwasita, T.; Hoster, H.; John-Anacker, A.; Lin, W. F.; Vielstich, W.; Langmuir 2000, 16, 522.

32. Camara, G. A.; Iwasita, T.; J. Electroanal. Chem. 2005, 578, 315.

Submitted: November 20, 2011

Published online: April 3, 2012

FAPESP has sponsored the publication of this article. 